which mental disorder is produced, represents an exceptional way. I am not hopeful that histological and chemical methods, pursued along the route that has been opened up in such an apparently obvious way, will throw light upon many more psychiatric problems, with the exception perhaps of certain forms of acute toxic psychosis. Greatly as I admire the precise and valuable results that have been reached in the case of general paralysis, I consider that the psychological work done by, for instance, the Freud-Jung school is not only more valuable at the present moment, but is infinitely more promising of fruitful results for the future.

\section{THE INTRAMUSCULAR TREATMENT OF SYPHILIS, WITH SPECIAL REFERENCE TO THE INSOLUBLE PREPARATIONS OF MERCURY: A CRITICAL REVIEW.*}

By GEORGE PERNET, M.D. PARIS, M.R.C.S. ENG., L.R.C.P. LOND.

TḦE protean manifestations, direct and indirect, of this infection meet the medical man at every turn, so much so that it may be said to dominate human pathology. Some writers have gone so far as to estimate that a third of the morbid conditions met with are accounted for by syphilis. ${ }^{1}$ Notwithstanding the great advance made in recent years in the direction of prevention, syphilis is spreading, thanks to the increased intercourse of nations with one another and rapid means of communication. Wars, too, are accountable for an increase in the incidence of the disease, so much so that in South Africa, for instance, syphilis has become a danger to the community. ${ }^{2}$ The moving about of large bodies of troops necessarily leads to the spread of venereal complaints, and I need not recall the great outbreak of syphilis at the time of the siege of Naples at the end of the fifteenth century. I have no doubt that the Cuban and Philippine campaigns have led to the spread of syphilis in the States. Again, the doubtful blessings of our civilisation can be bought too dearly by native races, such as those of Uganda, among whom lues venerea has become rife and threatens to exterminate, ${ }^{3}$ a recent example among many of syphilis conveyed to hitherto non-contaminated communities, as in the case of Pacific islands, for instance, infected by the early navigators. Where various preventive measures have been tried, some of them most drastic, they have defeated the very ends they were intended to attain by encouraging a security that was illusory.

I have mentioned these points, not by way of an apology for dealing with a subject of perennial interest, and likely for a long time to come to partake of that character, but to show that as far as syphilis is concerned we have a Sisyphean task before us. If we turn now from generalities as to distribution and spread to the particular, the individual, we find the domain of the disease being daily extended and to include every tissue in the body. Since the days of John Hunter, who by his great authority put the clock back as to our knowledge of visceral syphilis, ${ }^{4}$ although Morgagni had demonstrated the fact of its existence, one structure after another has succumbed to investigation. I would here insist on the enormous importance of recognising that the syphilitic infection is one that may affect any organ of the human body, and that the possibilities of future mischief are great, however benign the early visible manifestations of disease may appear to be.

It is germane to my subject to detain you yet a little longer on some cardinal points, which must, in my opinion, ever be borne in mind. We do not treat an abstract thing called syphilis, but a human organism suffering from the invasion of another organism, the spirocheta pallida or Treponema pallidum. That this organism must be accepted as the causa causans is, I think, settled. Every individual case must be treated on its merits. I have dealt with this at large in another place, ${ }^{5}$ but to prevent any misunderstanding I desire to say, in limine, that intramuscular injections, whether of soluble or insoluble preparations, are

* A paper read before the American Medical Association at its Sixtieth Meeting, Atlantic City, U.S.A., 1909. but one means, and a very valuable one, of treating the infection. Personally I am eclectic, and much depends on circumstances of various kinds as to the method to be em. ployed. Intramuscular injections, especially the insoluble ones, are not to be used in a routine manner for any and every case of syphilis. It is this routine, and, I may add, careless, manner of applying an otherwise admirable method that has been responsible for such undeserved disrepute. This is a point I shall have to go into at greater length later on. Another point, which $I$ think should be thoroughly grasped once for all, is that treatment should be started immediately the primary chancre is recognised as such, without waiting for so-called secondary or general manifestations. Indeed. all our powers should be directed towards the prevention of such symptoms by early energetic treatment guided by due and proper supervision of the case. Again, treatment should be pursued with perseverance and for a long period, for it has been amply demonstrated that inadequate treatment in the early years of the infection is fraught with future danger. It is now almost generally accepted as a fact, and further investigation serves but to confirm, that tabes "and general paralysis are syphilitic in origin.

Various changes in the blood-vessels ${ }^{7}$ leading to early and serious complications, unrecognised gummata of the heart terminating with sudden death, and so on, must be mentioned here. One of the latest conquests of syphilis is the involve. ment of the "band of His," giving rise to what has been called "heart block" or the Stokes-Adams syndrome-viz., incoördination in the rhythmic movements of the auricles and ventricles. Rénon ${ }^{14}$ records an instance in a syphilitic patient, who was distinctly relieved by pushing intramuscular injections of enesol. ${ }^{\prime}$ That cancer may develop as a result of syphilis is undoubted, especially since the work of Fournier, Butlin, and others concerning cancer of the tongue. Gaucher goes so far as to consider this condition as being always syphilitic in origin. ${ }^{9}$ Recent investigation again points very strongly to malignant disease of the uterus as a possible consequence of the syphilitic infection. ${ }^{10}$

Sufficient has been said in these brief introductory remarks to demonstrate the seriousness of the question of treatment, and is my excuse for calling your special attention to the intramuscular method. I am well aware that as far as the soluble preparations are concerned their employment is well known to you here in the United States, and it is not my intention, therefore, to detain you long as regards them. On the other hand, the insoluble preparations have not, if I may use the term, "caught on" either in my own country or in the United States-that is, as far as my knowledge goes concerning the latter, whereas in France these preparations are in current use. In England it is true, thanks to the efforts of Colonel Lambkin, mercurial cream injections are used in the British army, notwithstanding the adverse criticism of many well-known British dermatologists given in evidence before the Commission of Inquiry, ${ }^{11}$ although apparently they had had no actual experience of the method. Judging from the discussion that took place on the subject at the Sheffield meeting of the British Medical Association (Dermatological Section) last year this attitude is maintained, for Professor Neisser of Breslau and myself were the only two speakers who were resolutely in favour of the use of the insoluble preparations.

Now this negative attitude as regards a valuable method is explained by the fact that several fatal cases have been recorded as a result of the use, or more correctly the misuse, of "grey oil." It is therefore incumbent on me to examine some of these cases critically before going any further. In 1906 Claude and Dobrovici ${ }^{12}$ published five fatal cases following injections of grey oil. I will take them seriatim.

CASE 1.-A woman of 50 years. Injections of grey oil were given, gangrene of the pharynx.

CASE $2-A$ labourer of 25 years. Syphilis recent. He had four injections of grey oil during the month he was at the Hopital Ricord. Was admitted to the Hopital Saint-Louis with stomatitis. No albumin in urine. At the necropsy no evidence of pulmonary tuberculosis. Necrosis of left lower maxiliary.

In this instance no details as to doses injected are given. Howbeit, the fatal issue certainly appears to have been due to the injections.

Cask 3.-A café waiter, of 39 years. Admitted on Sept. 17th, 1904, to Saint-Louis for bad mercurial stomatitis. Old syphilis. Was treated for mental symptoms with loss of consciousness and epileptiform convulsions at another Paris hospital, receiving two series of six injections each with an interval of two months between them-viz., 
12 injections in all. On Sept. 29 th the patient was somewhat better as a result of treatment. $\Lambda$ troken-down gumma was discovered in the left anterior pillar of fauces. Ile was ordered a dally injection of 0.01 centigramme of benzoate of mercury (soluble preparation) with 2 grammes of iodide of potassium. By Oct. 5 th, although the gummatous condition improved, the stomatitis recurred. Injection stopped. Death occurred on Oct. 18th. $\Lambda$ t necropsy tuberculosis of lungs was found. Nothing said as to urine, but kidneys were large and soft with thickening of the cortex.

In this case we have a tuberculous patient, with kidnejs no doubt much below par leading to renal inadequacy. The occupation makes alcohol a possible unfavourable factor. Another point is the fact that he was ordered iodide of potassium, which increased elimination of the insoluble mercury preparation stored up in the body, for the last injection of the second series of six had been administered ten days before admission to Saint-Louis. In mercurial stomatitis iodide of potassium is in my opinion contra indicated, but in this particular case the gumma of the anterior pillar must be borne in mind. The exhibition of saline aperients is usually the best way of dealing with mercurial stomatitis, in conjunction with local treatment. To sum up, this case is one in which intramuscular injections of an insoluble preparation were distinctly contra-indicated from the first, and shows the necessity of dealing with cases on their individual merits after a thorough overhauling. The upper third of the right lung showed excavations, and would of itself have been sufficient to contra-indicate absolutely the employment of grey oil injections. ${ }^{13}$

Case 4.-A woman of 50 years. In January, 1905, she received five weekly injections of 6 to 7 centigrammes of grey oil for an ophthalmoplegia externa, which it shonld be added cleared up as a result of the treatment. Treatment was stopped immediately a stomatitic point was discovered about the last in ferior right molar. Notwithstanding all kinds of treatment the stomatitis went on progressively. The patient was admitted to the rards of Saint-Louis but she died on June 12th. There had been some albuminuria. The apices of both lungs revealed lungs revealed encysted tubercles, one of which was caseating capsules and atrophied cortices.

In this case a more thorough examination (urine, lungs) would have prevented the use of intramuscular insoluble injections, especially in the case of an elderly female, for women do not stand the insoluble preparations as well as men, nor in such large doses.

CASE 5.-A woman of 25 years; syphilitic; was treated in a Paris hospital in May, 1906, with grey oil. After an examination of the urine, which did not contain albumin, 10 centigrammes of metallic mercury were injected. A week later there was an improvement in her condition and 5 centigrammes were in jected. Immediately after this the patient felt out of sorts, and on examining her mouth a commencing right inferior molar stomatitis was discovered. She was admitted under Dr. de Beurmann. No pulmonary symptoms, no albumin, no diarrhoea She was put on a milk diet. At the end of a fortnight she left the hospital, improved, but not cured. Ten days later she was readmitted hospital, improved, but not cured. Ten days later she was readmitted
much worse, although she had had no mercury, with obstinate much worse, although she had had no mercury, with obstinate integument, with cedema of the face, arms, and legs. Urine became small in amount; albumin found.

Here, again, the intramuscular injections were evidently responsible, but it should be pcinted out that 10 centigrammes was too large a dose to start with in a woman, and, moreover, if the mouth had been examined for signs of stomatitis, as it should have been in a routine way, the second injection of 5 centigrammes would not have been given.

It must be noted that these five cases were hospital patients and it is only fair, I think, to assume that their nutrition was below the average. Another point of paramount importance is the condition of the teeth and mouth. In Europe the teeth of hospital patients are frequently in a very bad state, in many cases the use of a tooth-brush being unknown. In the five cases I have rapidly summarised the teeth are not mentioned. Possibly, too, although it is not stated, the stomatitis may have been aggravated in some of the cases, besides Case 3 , by the exhibition of iodide of potassium.

In addition to these five observations I would call your attention to some other bad cases which led to discussion at the Société Médicale des Hôpitaux de Paris ${ }^{14}$ in 1906. A woman, aged 38 years, admitted on March 22 nd, 1906, under Ménétrier and Bouchaud, developed a severe stomatitis of five weeks' duration five months after the injection of calomel. The teeth were in a very bad condition. She was discharged improved on April 1st. She returned on April 12th with a fresh outbreak of the stomatitis, when a nodule in the right buttock was discovered. It appeared she had had an injection on the left buttock in March, 1905, followed eight days later by an abscess which was opened, leaving a scar. A second injection was made into the right buttock in October,
1905, leaving a nodule or infiltration, which was excised. The urine did not reveal any albumin, but mercury was found in it. In this case the injection had been made in the subcutaneous fat and not into the actual muscle as it should have been. This is an important point, and it is necessary in fat patients that a needle of sufficient length should be used to ensure reaching the muscle.

In another fatal case, recorded by Letulle, ${ }^{15}$ a woman; aged 26 years, had had 20 injections of grey oil extending over four months, the patient being pregnant at the time. All went well at the confinement and a full-term child was delivered. On March 24th, the day before her admission to hospital, nother injection of grey oil was made, making 21 injections in all. A few hours later acute stomatitis occurred. The doses of the grey oil injected were unknown, as usual. Her teeth were in a deplorable condition; they were never attended to in any way during her confinement. Several decayed teeth were removed, with some improvement. But the stomatitis returned and the patient died. At the necropsy slight nephritis of some standing was found. Here we have to deal with an unjustifiable use of an insoluble preparation - viz., 20 injections in four months in a pregnant woman. It is well known that mercurial stomatitis is very likely to occur in pregnancy and the puerperium when the woman is in a toxic condition already. 20 Pregnancy contra.indicated the insoluble injections. Moreover, women are in any case more prone to develop stomatitis than are men. ${ }^{17}$ The doses injected were not known, a fact which crops up frequently in the records of fatal cases. In addition, the patient's teeth were evidently in a condition that should have been an additional contra-indication to the employment of insoluble injections.

In the discussion Queyrat, who had had a large experience at Cochin-Ricord, said he had never seen any serious symptoms following the use of intramuscular injections of gréy oil, even in larger doses than was usual, although 6000 and more a year were carried out in his department. $\mathrm{He}$ pointed out that in some individuals nodules occurred, and in such it was wise not to persevere with insoluble preparations if nodules followed the injections on two consecutive occasions. In this I agree, for it must be remembered that in cases of that kind a large amount of mercury may subsequently be suddenly thrown into the system. In some cases deposits of mercury have been revealed by $X$ rays. and excised, thus cutting short the stomatitic symptoms.

Duhot, who for some years now has employed the insoluble preparation of mercury on a large scale and followed up his cases in a very thorough manner, has published his results in a recent paper. ${ }^{19}$ As regards "grey oil," during the three years 1906-7-8 he has dealt with 781 cases of syphilis (primary, early and late congenital) in hospital and private practice (some 7800 intramuscular injections), and including cases previous to 1906 has had an experience. of over 20,000 injections in all. Taking the year 1908 (289 cases in hospital and in private 253-141 hospital and 121 private of which were treated by means of injections of grey oil, about 4500 injections) he never met with any serious complication as a result of the intramuscular treatment ("huile grise"). The doses varied from 7 to 14 centigrammes. In neither class of practice was there any case of stomatitis. In three hospital cases a superficial abscess was observed due to a fissure in the needle. Here I máy observe that needles (platino-iridium) require supervision as to cracks, thus leading to a deposit of the grey oil in the superficial parts. 15 nodules (10 hospital, 5 private) occurred. By nodule is meant a nodular infiltration or small lump in the muscle. Slight gingivitis, 6 (4 hospital and 2 private). Thoracic pain or constriction, 9 (6 hospital and 3 private) Mercurial grippe, "grippe mercurielle" "fièvre merourielle" of Emery, that is general malaise, slight febrile manifestations, pains about the limbs and joints, loss of appetite, headache, \&c. ; in a word, symptoms resembling influenza or grippe. ${ }^{20}$ Albuminuria : 8 hospital, and fleeting in 3 private cases. Intolerance : 3 hospital and 1 private, all these cases were observed in women; this emphasises what I have already said as to women not standing the injections as well as men.

Jullien ${ }^{21}$ was the first to contend that the early (secondary) manifestations of syphilis could be systematically prevented by energetic treatment-viz., by intramuscular injections of calomel. Duhot held the same opinion for a time but subsequently he gave up calomel for grey oil, and he now puts 
forward 200 cases he has had under observation, and claims that as a result of energetic "abortive" treatment, as he calls it, by intramuscular injections of grey oil in large doses started immediately on the early diagnosis of primary chancre, there has been no sign of tertiary manifestations. ${ }^{22}$ of course, as we all know, the tertiary symptoms may be long delayed, and this is a fair objection that might be made as to the point he has put forward. As to doubt about the diagnosis of the primary syphilis, he has laid this at rest by a systematic examination for the Treponema pallidum by demonstrating its presence in smears and frequently in the excised chancre, this being ascertained in a routine way before starting the treatment. When the treatment was commenced after the appearance of the secondary or early rash, tertiary manifestations have occurred but they have been rare, thus emphasising the necessity of early interference. I have already insisted on the importance of such a procedure, but it will bear repeating again and again, so great is the infuence of authority, especially as it is still maintained in some quarters that one should wait for the secondary rash before commencing treatment, although that attitude is slowly breaking down and giving way to a more rational view of the matter. Moreover, Duhot further insists that in his cases (134 at the time he wrote on the point) cerebro-spinal lymphocytosis as ascertained by lumbar puncture did not occur. In addition to this, Duhot, with the assistance of De Grave, is applying the Wassermann test to cases treated by the abortive method. They have found that the negative Wassermann test is in direct ratio to energetic early intensive treatment.

Scherber, in the clinic of Finger at Vienna, has also obtained encouraging results with the "abortive" treatment by excision of the primary sore and intramuscular injections of either mercury salicylate or "huile grise," but mainly the former. ${ }^{23}$

Neisser has also employed large doses of grey oil, following on Duhot's initiative, that is, 14 centigrammes. In a recent communication Zieler (now of Würzburg), working in Neisser's Breslau clinic, places on record that injections of large doses of grey oil are well borne, and states that in 50 cases treated in that way, totalling 271 injections of 14 centigrammes, no untoward complication was observed, and that even in the case of women such large doses could be frequently employed, but that in them marked infiltrations (nodules) were observed in several instances. ${ }^{21}$ Zieler insists, however, on the importance of using the new preparations of grey oil in this respect, and points out, as I have already done, that women do not bear the injections as well as men, and that it is incumbent in their case to use smaller doses-viz., 5 to 7 centigrammes.

Another recent paper on the subject by Carle must also be alluded to. In 282 cases (1902 to 1907) Carle employed the abortive treatment early and "intense," with very satisfactory results as to secondary and tertiary symptoms, ${ }^{25}$ and on the whole he confirms the results of Jullien, Duhot, Leredde, Tommasoli, and others ; but Carle does not consider that abortive, intense, early treatment prevents in all cases subsequent morbid manifestations. He also expresses the opinion that in rare instances the iodides and arsenic are valuable, especially in the malignant forms.

It would be impossible in the present paper to go into all the literature of this big subject, but I think I have said enough to show that when the intramuscular injections of grey oil are carried out with care and with the precautions that I shall enumerate further on, serious complications do not arise. In the foregoing it has been my endeavour to deal with the matter fairly and squarely, for we must aim as medical men at doing all we can for the benefit of our patients. I have placed before you the dangerous possibilities that lurk in the treatment unless carefully applied, and I should certainly not advise any and everybody to attempt it unless the method has been mastered. I repeat once more that it is not a routine treatment which can be carried out in a haphazard manner.

As far as my own work goes, I may say that I have only employed the intramuscular injections of insoluble preparations in my private practice. I have never seen any complication arise. My results have been very satisfactory and I consider the method a most valuable one, especially when any serious syphilitic complication threatens. My experience of the early abortive intensc treatment has been from the nature of private practice very limited, and I have not felt justified in applying it to its full extent. But where full control of the patient could be obtained I have found no ill-effects ensue after 10 or 12 consecutive weekly injections of doses varying from 7 to 10 centigrammes. Indeed, the results have been in a few instances of this kind very encouraging. In one case the primary sore was followed by high temperature in a patient who had previously suffered from malaria, and who, as is usual in such an event, considered the febrile condition of that nature. I considered the temperature was syphilitic, and on that assumption I injected grey oil, as I have stated, with the best of results. Since then several series of injections of grey oil have been given, and the patient has done extremely well as far as syphilitic sym. ptoms are concerned. The injections have been well borne, although the patient had been liable to pseudo-dysenteric attacks. Salicylate of bismuth in gr. v. cachets three times a day is efficient as a rule in dealing with any tendency to attacks of diarrhoea.

Before leaving grey oil it is necessary to state that a properly made sterilised standard preparation should be used. As far as I am concerned, I have always employed French preparations and I have found them reliable in their action. Grey oil is now in the French Official Pbarmacopceia. The formula is: purified mercury, 40 grammes; anhydrous lanolin, pure and sterilised, 26 grammes; medicinal oil of vaseline sterilised, 60 cubic centimetres. This is put up in small glass-stoppered bottles of 1 cubic centimetre of the preparation containing practically 40 centigrammes of mercury. I now use Lafay's standard preparation, but there are other good brands such as Vigier's, Roger-Cavailles's, \&c. I am obliged to mention this, as it is of the greatest importance, as you will see, to use a uniform grey oil, for some of the accidents which have been placed on record have been the result of using much too large doses in error, and in one case of employing a preparation put up by a pharmacist who made a mistake in reading the prescription (Smirnoff's case). By employing a standard preparation of one strength and a syringe one is accustomed to, there is no chance of confusion and of errors, which may arise when different strengths and variously graduated syringes are used.

Accidents with grey oil, and also with calomel, have occurred-that is undoubted, and I insist on the fact. But accidents have also followed the use of soluble preparations and fatal cases have resulted from inunctions. With regard to the latter I will mention two cases. In the case of a very fat woman, G. Mayer ${ }^{26}$ of Aachen records a fatal termination following the use of inunctions, which led to a severe generalised eczema, as he calls it, but which was probably what we should more correctly designate mercurial dermatitis. Stein ${ }^{27}$ has quite recently given the details of a fatal case occurring in a young woman of 26 years, with recent syphilis, who developed severe dermatitis after 24 rubbings of 3 grammes each of unguentum hydrargyri, from Nov. 18th to Dec. 17th, accompanied by fever and very severe complications. The patient died seven weeks after the commencement of the treatment. At the necropsy, numerous punctiform hæmorrhages were found in the muscles of the trunk, in the endocardium, the liver, the kidneys, and the intestinal mucous membranes. It will be noted that once more the patient was a woman, a point to be borne in mind. There is no doubt the rubbing was over-done. Moreover, when the erythema started, iodide of potassium was administered, a proceeding which I consider a mistaken one-a fact I have already insisted on. These are not the only two cases that might be brought forward against the inunction treatment. But that would surely be no reason for damning a method that is valuable. Philosophically considered, everything is relative, just as much in medicine as in any other sphere of human activity and endeavour.

In my own experience I have found that patients suffering from the effects of fairly recent malarial and tropical infections, such as blackwater fever, bear inunctions badly. In one instance, two or three inunctions led to severe stomatitis, although the mouth had been put in order, and the patient was confined to his bed and kept under strict observation. A fortiori in such cases would intramuscular injections of insoluble preparations be contra-indicated, and soluble preparations would have to be closely watched. In the particular case I have referred to I found arsenic very valuable. That was before atoxyl, but they are the sort of patients in whom a properly prepared atoxyl should prove useful.

In connexion with my subject, I must allude to an 
instructive and unusual case of indirect mercurial intoxication terminating fatally and occurring in a tuberculous male of 21 years related by Volk. The patient was admitted to a venereal ward in Vienna on account of an ulceration which had been thought to be luetic but was really tuberculous. The cubic capacity of the ward was about 750 cubic metres and contained 24 patients. Five or six of these were being treated by means of Welander's mercury bags, whilst others at the time were not having inunctions or other external mercurial treatment. Nine days later the tuberculous patient developed mercurial stomatitis, and notwithstanding the fact that he was moved to another ward he rapidly sank with symptoms of lobular pneumonia and cedema of the lungs, the stomatitis having meanwhile become worse and worse. ${ }^{28}$ Here we have a rare example of indirect mercurial intoxication, but it must be observed occurring in a tuberculous non-syphilitic patient.

This case reminds me of an instance of bad stomatitis in a male with old syphilis following inunctions. The stomatitis made no headway towards recovery when the inunctions were stopped and the condition treated by appropriate remedies, but I discovered that the patient was still wearing the singlet he had worn during the inunction period and which was still soiled with unguentum hydrargyri. He was inhaling mercurial vapours, especially at night. When this was removed his stomatitis soon improved. If I have referred to toxic complications arising from other methods, it has not been with the intention of condemning them, but in order to show that no method was perfect, and that intramuscular injections of insoluble preparations especially were not to be thrown on one side because accidents, in most if not all instances avoidable, had followed their use.

I take this opportunity of calling your attention to another point of importance-viz., that complications laid at the door of mercurial treatment are not infrequently really due to the syphilitic infection itself. This is a subject I cannot deal with in this place at any length, but symptoms of that kind, such as fever, albuminuria, and so forth, will readily occur to you. Moreover, this side of the question has already been thoroughly dealt with by Emery and Lacapere ${ }^{29}$ and others, so I will pass on to the consideration of matters more nearly related to my present paper.

Having touched on grey oil, I must now say a few words on the subject of calomel, first employed subcutaneously and then intramuscularly by Scarenzio in $1864 .{ }^{30}$ Jullien, who had experimented with a variety of mercurial preparations, soluble and insoluble, came to the conclusion that calomel in intramuscular injections was a sovereign remedy and one which, when used carefully, could be employed with safety. He instances, for example, two cases of early optic neuritis which cleared up under its use. ${ }^{31}$ In serious manifestations of syphilis, of the brain, eye, and so forth, calomel is a sheet anchor. Leredde, Babinski, and other observers have shown its value in syphilitic affections of the nerves. Darier, in speaking of threatening specific cerebral arteritis, is very categoric on the point, and rightly so. He advises the immediate injection of 10 centigrammes of calomel in the case of men, and 5 to 7 centigrammes in the case of women, continuing them every fifth or eighth day, but when the mouth is in bad condition a daily injection of a soluble preparation (biniodide, benzoate, cyanide) is to be preferred. ${ }^{32}$

In the initial manifestations of early syphilitic hemiplegia the use of calomel may make all the difference in the future of a young man. I have myself seen a promising career wrecked by not keeping this point well in view. The patient was a young adult from abroad, whom I saw for the first time a year after the hemiplegia had become confirmed. In the quite early stages of his cerebral syphilis he had been treated in London by mercurial pills, an utterly inadequate treatment. When he came under my observation for the first time, a year later as I say, there was nothing to be done, the arm having become ankylosed at the shoulder-joint, with contractures. This case made a great impression on me. Now had this young man been injected with calomel from the very onset there is every probability the hemiplegia would have been averted. And it is all very well to say that the insoluble preparations may lead to complications in the way of mercurial intoxication, but in desperate junctures the consequences of the syphilitic infection, as in this case, may be more damaging still.

One of the objections made to calomel is that the injections are very painful. They may be, although patients vary a great deal in this respect. I have not found Zambeletti's calomel preparation lead to any pain, or at most it has been slight or very bearable. Recent experimentations by Lévy-Bing, Eudlitz, and Lafay tend to show that concentrated calomel preparations are better borne than those usually employed. They have settled on a preparaion containing 40 centigrammes to 1 cubic centimetre, instead of using those in the market containing only 5 or 10 centirammes to 1 cubic centimetre. ${ }^{33}$ This dosage has the urther advantage of assimilating it to the "huile grise" of the French codex, thus leading to simplification in practice.

There is a syphilitic symptom which is of great importance and not infrequently overlooked, I mean the characteristic headache coming on towards the evening (vesperal), or occurring at night (nocturnal), and which calls for energetic and immediate treatment by means of intramuscular injections of insoluble or soluble preparations, as the case may be. In dealing with the insoluble preparations, and especially "grey oil," I have referred mainly to French medical literature, for the simple reason that it is in France that they have been mainly employed. In England and the United States this method of treatment has not been applied to any extent, but only made use of sporadically.

Although I have subtitled my paper a critical review, one of its objects is of the nature of a plea in favour of valuable preparations likely to prove of the very greatest service in combating so fell and protean an infection as syphilis, and in preventing some of its direst consequences, disastrous alike to the individual and the community. I make no apology, therefore, for bringing the matter before you, and I am sure that with your active American minds, so quick to seize on the practical aspects of life, you will have grasped the force of the evidence which I have placed before you. I have done this in a fair and impartial manner, being fully alive to the responsibility which such a presentation entails. This fact makes it necessary that I should detain you yet a little longer in order to touch on the technique of the insoluble injections.

In dealing with this part of my subject to save time I will give the details of the manner in which I myself carry out the intramuscular injections, but in the bibliography which I have appended references will be found by those wishful of going more thoroughly into the matter; indeed, it is very desirable that anyone contemplating the employment of the method should make a point of doing so. ${ }^{34}$ For the insoluble preparations the Edmond Fournier and the Léry-Bing-Lafay syringes should be used and not an ordinary Pravaz, as usually recommended. The Fournier model is all glass and of $\frac{1}{2}$ cubic centimetre capacity, divided into ten on the barrel, so that each division represents 2 centigrammes of mercury or of calomel, the standard preparations being, as I have said, 40 centigrammes of mercury to 1 cubic centimetre (huile grise) and 40 centigrammes to 1 cubic centimetre (concentrated calomel preparations) respectively.

The Lévy-Bing-Lafay syringe has been specially devised for the 40 centigrammes to 1 cubic centimetre preparations. It is all glass and nickel with bayonet adjustment for the cap, making the parts readily detachable. In this syringe the piston rod itself is graduated, being divided into 15, each division representing 1 centigramme of the 40 centigrammes to 1 cubic centimetre preparation (huile grise and calomel) thus rendering the instrument very practical. Fifteen centigrammes is the maximum dose that may in certain very special cases be employed without producing toxic effects, but I would warn you that it is advisable to be satisfied as a rule with doses not exceeding 10 centigrammes for men and 5 to 7 centigrammes for women.

As to the Zambeletti preparations of calomel they are put up in phials containing 5 to 10 centigrammes of calomel, so that any good ordinary glass syringe can be nsed. The syringes are sterilised by boiling in the usual way. As to needles, they are of iridized platinum with gold mounts, and can be passed through a flame before fitting to the charge syringe, but I prefer to boil them at the same time as the syringe. Their length is an important matter in the case of the insoluble preparations with which I am at present concerned-viz., not less than 5 centimetres. But needles of various lengths are required: $6,7,8$ centimetres for fat subjects, in order to get the preparation well into the muscle. The bevelled end must be kept sharp to avoid giving pain. This is effected by means of small pieces of Arkansas stone. The lumen must be sufficient, but not too large. The needles 
can be kept in paraffinum liquidum or in alcohol. Before using them their permeability must be ascertained.

With regard to the parts of the buttocks where the injections are to be made I have come to the conclusion that an area round a point midway between the gluteal cleft and the anterior superior iliac spine is the most useful. LévyBing ${ }^{35}$ has gone into the matter by means of actual dissections and gives the following directions. Through the middle of a line joining the gluteal cleft and the anterior superior iliac spine he drops a perpendicular, and describes a circle with its centre at the point of intersection and with a radius of three centimetres. In each of the quadrants thus formed he makes an injection. There are also other suitable positions, ${ }^{36}$ but the point is to keep to the upper parts of the buttocks well away from the danger zone of vessels and nerves, which can be readily ascertained by a reference to anatomical plates ${ }^{37}$ or to bodies in the dissecting room.

The following is the modus operandi. The injections should be made with the patient lying on a couch in the prone position. The part of the buttock selected must be thoroughly sterilised (soap, ethereal soap, alcohol, ether, and so forth). The sterilised needle is then attached to the nozzle of the empty sterilised syringe and plunged perpendicularly and rapidly through the skin into the subjacent muscle. The piston is gently drawn up two or three times in the barrel in order to make sure that the point of the needle has not penetrated a vessel. If any blood appear the needle may be either withdrawn a little and the test repeated or withdrawn altogether and arother spot selected. It is, I need scarcely add, important not to inject an oily preparation into the lumen of a vessel. Personally, I have never drawn blood up in the syringe on applying this preliminary test, but nevertheless I always make the trial as a matter of routine. The barrel is then detached from the needle, which is left in place. The "huile grise" or calomel is then drawn up into the barrel directly from the flacon, an easy matter with Edmond Fournier's small calibre syringe. Here it is necessary to point out that the mercurial preparations should be slightly warmed, not heated, and well shaken up before charging the barrel. The dose required, 5,6 , or more centigrammes, as the case may be, is then drawn up into the barrel, which is re-attached to the needle, and if no blood has appeared at the mount of the needle the dose is slowly but firmly pushed home in the muscle. Duhot recommended that after this has been done some air or a little sterilised saline solution should be drawn up into the barrel, detached for a second time for that purpose, and in its turn pushed home in order to clear the needle of any preparation remaining on it, and thus avoid leaving a track of grey oil when the needle is withdrawn. Tracks of this kind may lead to small superficial furuncles. I have always used air and I have never seen any untoward result ensue. There is no need to massage the part, as is sometimes recommended. The orifice is covered with a small piece of zinc oxide plaster or collodion and wool. A careful record should be kept of the quantity injected at each sitting and the point injected. In the case of these insoluble preparations one injection a week is the rule. The injections should be made in the right and left buttock alternately. In every case, and especially when the insoluble preparations are employed, the patient should be previously thoroughly overhauled as regards the state of his mouth, the condition of the urine as to albumin, \&c., his weight estimated, and so forth. I have already insisted on the condition of the teeth, any defect being put right by a dental surgeon before starting the treatment. This is an essential point, and may mean everything as regarded the future course of the treatment. During treatment the urine must be watched, as also the state of the gums and buccal mucous membranes, by examination with the frontal mirror and reflected light, in order that any warning may bid you to stop the injections.

Again, I would insist that all methods have their advantages and disadvantages. In selection one must be eclectic and it is of the greatest importance not to go off one's head in favour of any one method to the exclusion of all others. Every case must be dealt with on its merits and the various circumstances surrounding it taken into account. Injections of insoluble preparations must not be employed in a routine manner for all and sundry. In some cases they are absolutely contra-indicated, as in old people, the brokendown, the bed-ridden, paraplegic, and those with renal inadequacy or presenting albuminuria, patients suffering from tuberculosis, lead-poisoning, or decidedly gouty, and alcoholics. I have already called attention to the unsuitability of cases suffering from the devitalising effects of malaria and tropical fevers, as also of pregnant women. One must be specially careful in the case of women.

On a variety of other points I would refer you for full details. to the quite recent contributions of Emery and Chatin, whose exhaustive and thorough work will well repay study, and of Lévy-Bing, who has written a succinct monograph on the subject. ${ }^{34}$ Although I have dealt mainly with the insoluble preparations of mercury, for reasons stated, I have no desire to minimise the value of the soluble salts. The latter are often of the greatest utility, and I would here testify to the good results I have obtained with the hypertonic benzoate of mercury as prepared in accordance with the directions of Professor Gaucher. There are also a number of mercurial solutions, which all have their place and with which you are familiar.

In conclusion, I desire to thank you, Mr. President and gentlemen, for the opportunity you have given me of submitting the foregoing remarks to your judgment and for the honour you have done me in inviting me to take part in the work of your great Medical Association.

Bibliography.-1. Gaucher: Le Chancre et les Syphilides, 1907, Preface.-2. Pernet: Increase of Syphilis in London since South African of the Cape of Good Hope (1904, p. 1196 and p. 1778. Health Reports pp. xcv. et seq.), 1905, \&c. (Also Brit. Med. Jour., vol. 1i., 1904, p. 1423; also Australasian Medical Gazette, Dec. 21st, 1908, p. 674).-3. Lambkin: An Outbreak of Syphilis in Virgin Soil (in A System of Syphilis, 1908, vol. ii., p. 339). - 4. John Hunter: A Treatise on the Venereal Diseases, vol. i., 1907, p. 730, with bibliography.-6. Gowers: The Nature of Tabes, Brit. Med. Jour., vol. i1., p. 57 (Pernet's Figures for Male Cases of Syphilitic Skin Diseases, p. 59, col. ii.).-7. Darier: De l'Artérite Syphilitique, 1904 (an important and exhaustive monograph).following is Sawyer's description of the band of His: ". $A$ singular following is Sawyer s description of the band of His: A singular branches in the ventricular walls, and forming a union between auricle branches in the ventricular walls, and forming a union between auricle one to the other." (Points of Practice in Maladies of the Heart, 1908, p. 28.)-9. Gaucher: Cancer de la Langue (in Le Chancre et les. p. 28.) -9. Gaucher: Cancer de la Langue (in Le Chancre et les. important contributions to the subject from the surgical point of view in the British Medical Journal, 1908-1909. His plates show leucoplakia in many instances. Butlin and Spencer: Diseases of the Tongue, 1900。 Groll: Cinq Observations de Syphilis et Néplasmes, Grenoble, 1906.10. Franceschini: L'Origine Syphilitique de quelques Cancers
Utérins (Annales des Maladies Vénériennes, 1906, p. 241.-11. Reports of the Advisory Board for the Army Medical Service (on the Treatment of Venereal Diseases and Scabies), London. - 12 . Claude et Dobrovici : Cinq Cas de Mort à la suite d'Injections d'Huile Grise (Sur une Forme de Stomatite et d'Angine Gangréneuses imputable a ce Médicament), Annales des Maladies Vénériennes, vol. i., 1906, p. 96. See also bibliography attached of other instances of intoxication. Also Gaucher: Le Traitement de la Syphilis, second edition, p. 8.13. As to Relations of Tuberculosis and Syphilis: See Patoir : Syphilis et Tuberculose, La Presse Médicale, No. 5, 1901, p. 25. Emile Sergent: Syphilis et Tuberculose. A monograph, 1907. Bernhart of Chicago: Miercury and Tuberculosis, New York Medical Journal, June 27th, 1908 , p. 1236 . Bernhart does not appear to distinguish sufficiently between the tuberculous who acquire syphilis and the syphilitics who become subsequently tuberculous. Hebruary, 1909 , p. 129.-14. Bulletin de la societe de Medecine des.
Hôpitanx de Paris, tome xxiii., 1905.-15. Loc. cit., supra.-16. See also Hopitaux de Paris, tome xxiii., 1905.- 15 . Loc. cit., supra. -16. See also
on this point Kraus: Erkrankungen der Mundholale, Nothnagel's Sn this point Kraus: Brkrankungen der Mundholle, Nothnagel's Specielle Pathologie und Therapie, xvi., Theil I., Abteil I., 1897, pp. 142 et seq. - 17. See Tables in Lanz: Die Pathogenese der Mer18. See Noiré : Radioscopie et Traitement Mercuriel, İ a Clinique, 1907, Mars, p. 201.- 19. Duhot: Statistique des cas de Syphilis observés pendant l'année, 1908; 22,500 Injections d'Huile Grise sans Accident périanx. Confirmation du Traitement Abortif de la Syphilis. Le Sérodiagnostie, Annales de la Policlinique Centrale de Bruxelles No. 909, p. 33-20. Emery et Chatin : Thérapentique Clin'que de la Syphilis, 1908, pp. 106-107.-21. Jullien. Du Traitement Mercuriel Intense et Précoce du Début de la Syphilis, Rome Congress, 1897. -22. Duhot: Loc. cit. supra (19), p. 89. See also Duhot.-23. Scheiler: Die Abortivbehandlung der Syphilis, Verhandlungen der Deutschen Derm. Gesellsch., Tenth Congress, 1908, p. 243.-24. Zieler: Ueber die Verwendung hochprozentiger Queck-silbermischungen (graues Oel Kalomelöl) zur Syphilis-behandlung, Munchener Medizinische Wochenschrift, No. 46, 1908, p. 4 of reprint.-25. Carle : Essai sur le Traitement Intensif et Précoce de la Syphilis (Traitement dit Abortif), Lyon Médical, 19 Avril, 1908, pp. 15 et seq., of reprint.-26. G. Maver : Ueber die Prognose der Syphilis, 1904, Medizinische Wochenschrift, 1908 , No 49 , Dec 3 ind Deutsche 28. Cited by Volk in Die Injectionstherapie der Syphilis (Dermatologische Zeitschrift, Band xv., Heft 10, p. 605), but originally published by Wolfsohn, Jahrbuch der Wiener Krankenanstalten, 1898.-29. Wmery et Lacapère: Diagnostic des Accidents d'Intoxication Mercurielle et des Aceidents de la Syphilis, Annales res Maladies Vénériennes, 1908, vol. iii., p. 907.- 30. See Soffiantini : Transactions of the International Congress of Dermatology, London, 1896, p. 375.-31. Jullien: Les Injections Mercurielles, Journal des Maladies Cutanées et Syphilitiques, December, 1904, p. 5 of reprint.-32. Darier: Op. cit. (7), p. 139.-
33. Eudlitz, Lafay, Livy-Bing: Une Nouvelle Préparation de Calomél Injectable, Annales des Maladies Vénériennes, vol. iii., 1908, p. 196. See also Lévy-Bing: Les. Injections Mercurielles Intramusculaires 
dans le Traitement de la Syphilis, 1909, p. 37.-34. Nimery et Chatin: Thérapentique Clinique de la Syphilis, 1909; Lévy-Bing : Les Infections Mercurielles Intramusculaires dans le Traitement de la Syphilis, 1909. See also Fournier, Le T'raitement de la Syphilis Gaucher, Traitement de la Syphilis, second edition; Lambkin, in A System of Syphilis, vol. ii., 1908, pp. 255 et seq.; Jacquet et Ferrand, Le Traitement de la Syphilis.-35. Livy-Bing : Op. cit. (34), p. 22, Chatin: Op. cit. (34), Figs. 8 and 9, pp. 155 and 157 . Harley-street, $W$.

\section{AN INVESTIGATION INTO THE ACTION AND USES OF FIBROLYSIN IN MIDDLE-EAR DEAFNESS.}

BY J. GAY FRENCH, M.S. IOND., F.R.C.S. ENG., SURGEON-IN-CHARGE OF THE EAR, NOSE, AXD 'IHROA'T OI'T-PATIENTS, GREAT NORTHERN CENTRAL HOSPITAL ; ASSLSTANI SUR(+EON TO THE CENTRAL LONDON EAR, NOSE, ANI THROAT FIOSPITAI, GRAY'S INN ROAD, W.C.

IN 1892 von Hebra ${ }^{2}$ published the results he had obtained with a 15 per cent. solution of thiosinamine in alcohol in the treatment of lupus and cutaneous scars. He used this solution by the injection method and showed that it had a very marked action in dissolving pathological fibro-cicatricial tissue. Thiosinamine is a substance which is chemically known as allyl-sulpho-urea. It is prepared from oil of mustard and occurs in colourless monoclinic or rhombic crystals with a bitter taste and an odour of garlic. It is an unstable compound, insoluble in water, but dissolving freely in alcohol. The physiological action of thiosinamine is, in the first place, to cause a diminution of the number of leucocytes in the blood, followed later by a very considerable increase. Its action on scar tissue is very definite. Macroscopically, after an injection a reddish scar, such as that after a burn, becomes paler, swollen, and more flexible, and the limited movements of the parts bound down by the scar tissue are increased in range, but after a short time these phenomena disappear. If, however, the injections are repeated at short intervals it is found that the abovementioned conditions become permanent. Microscopically, turgescence is seen to take place in the individual connective tissue fibres; their outline becomes blurred and indistinct, the nuclei are pushed aside and appear more prominent, and the whole tissue becomes swollen and looser in texture. A curious feature of thiosinamine is that its action is only exerted on pathological fibrous tissue. The objections to its use are its instability, its insolubility, and the extreme irritation caused by the injection of its alcoholic solution. Felix Mendel ${ }^{2}$ of Essen, however, discovered that by the combination of two molecules of thiosinamine with one of salicylate of soda a substance was produced which was easily soluble in water, was comparatively stable, and did not give rise to any irritation on the injection of its aqueous solution. To this substance - which retained all the properties of thiosinamine - was given the name of "fibrolysin."

I first saw the beneficial results obtained by its use some three years ago in two cases. The first was one of Dupuytren's contraction of the fingers, in which a fair, though not very good, result was obtained. The injections were given about once a fortnight, the fingers were frequently moved, and the hand was placed on a straight splint in the intervals; the result would in all probability have been much better had the injections been given twice a week instead of once a fortnight. The second was a case of Volkmann's contracture (the so-called ischæmic paralysis), in which a very excellent result was obtained after frequent injections. These results led me to think that fibrolysin might prove a very valuable therapeutic agent in the treatment of aural cases, and particularly in those where, as a result of suppuration or catarrh, a development of fibro-cicatricial tissue had taken place in any portion of the conducting apparatus of the ear.

In my first series of cases the results were not generally satisfactory; some cases certainly showed fair improvement, but the greater majority were in no way benefited. At this time I had been giving the injections once a fortnight, and I determined to increase them to twice a week and at the same time to apply it locally to the middle ear through an Eustachian catheter-a method employed with success

Von Hebra: Intern. Klinische Rundschau, Sept. I1th, 1892. 2 Felix Mendel: Therapeutische Monatshefte, February and April,
1905; and Therapie der Gegenwart, August, 1905. by André Horeau in connexion with thiosinamine. The results immediately improved. The method which I employ is to use one ampulla of fibrolysin containing $2 \cdot 3$ cubic centimetres-roughly 40 minims-as follows: 30 minims are injected subcutaneously into the upper arm, and 5 minims are insufflated through an Eustachian catheter into each middle ear. After an interval of 15 minntes massage is applied on cach side for from three to five minutes by means of an oto-masseur. This routine is gone through twice a week for six weeks ; if at the end of that time there is no definite improvement my experience is that the case is a hopeless one, and that it is useless to persevere with the treatment.

The cases in which I have systematically carried out this treatment are those of deafness and tinnitus resulting from (1) post-suppurative middle-ear catarrh, where there bas been a cessation of discharge with formation of scar tissue and destruction or ankylosis of the ossicles; and (2) chronic dry middle-ear catarrh-i.e., non-suppurative catarrh-retracted membranes, with or without ankylosis of the ossicles.

The number of cases that have had the six weeks' treatment have been 68 . Of these, 21 were cases of postsuppurative middle-ear catarrh and 47 were cases of chronic dry middle-ear catarrh. Of the 21 cases of post-suppurative middle-ear catarrh, 16 had tinnitus and five had no tinnitus. of the 16 with tinnitus, four were complete failures; there was no improvement in hearing or diminution in the noises -indeed, one patient stated that she was much worse in both respects. Six had no improvement in hearing, but stated that the noises were less; two of these stated that the noises had completely ceased, and they thought they could hear a little better (this, however, was not borne out by the tests). Six showed good improvement in hearing to the tests, and stated that the noises were diminished in three, completely ceased in two, and no better in one. Of the five cases with deafness but with no tinnitus, two showed no improvement and three showed improvement. Of the 47 cases of dry middle-ear catarrh, 36 had tinnitus and 11 had no tinnitus. Of the 36 with tinnitus, 11 were complete failures ; eight showed no improvement in hearing to the tests, but stated the noises to be diminished (completely ceased in two); and 17 showed improvement in hearing to the tests, and of these, six stated that there was no diminution in the noises (though in one they had become intermittent instead of being constant), eight stated the noises to be diminished, and three reported the noises to have quite ceased. Of the 11 without tinnitus, seven showed improvement to the tests and four showed no improvement.

In order to prove that it was the fibrolysin and not the Eustachian catheter and the oto-masseur which brought about the improvement, 15 of the above cases-all with tinnitus as well as deafness-were first treated by the catheter and massage for six weeks without having any fibrolysin, and their tests taken; they were then put on the fibrolysin course, and at the end of the six weeks of fibrolysin treatment their tests were again taken and the three sets of tests were compared. It was found that in seven out of the 15 there was no improvement in hearing, though two out of these seven reported diminution in the tinnitus. The accompanying table shows the improvement in the eight case. which received benefit-three of post-suppurative middle-car catarrh and five of chronic dry middle-ear catarrh.

It will be seen that in Cases 1 and 5 there was a slight improvement in both ears after the six weeks' catheterisation and oto-massage, but a very much greater improvement took place under fibrolysin. It will also be noticed that the postsuppurative cases gave more consistently good results-i.e., greater improvement-than did the chronic dry catarrhs; moreover, in all the above, with two exceptions, the tinnitus was improved and in one it had quite ceased.

I turn next to the question of the permanency of the results obtained. Of the 16 cases showing improvement in hearing and diminution in tinnitus, ten were treated a year ago or over and have had no treatment since; four were cases of post suppurative middle-ear catarrh. Of these one only has had a relapse in both hearing and tinnitus; in two the improvement in hearing is maintained, but the noises slightly returned; and in one the improvement in hearing is maintained and there has been no return of the tinnitus. Six were cases of the dry catarrbal type. Of these two have relapsed (one patient states that she is just as bad as ever, the other has had a return of the tinnitus and there is a slight diminution in 